\title{
In vivo physiological research in the US: regulatory and ethical issues
}

\author{
This article was published in the following Dove Press journal: \\ Open Access Animal Physiology \\ 15 December 2014 \\ Number of times this article has been viewed
}

\author{
Charles C Cates' \\ Marcelo A Couto ${ }^{2}$ \\ 'Department of Comparative \\ Medicine, Cedars-Sinai Medical \\ Center, Los Angeles, CA, USA; \\ ${ }^{2}$ Department of Laboratory Animal \\ Medicine, David Geffen School \\ of Medicine at the University of \\ California, Los Angeles, CA, USA
}

Correspondence: Charles Cates Department of Comparative Medicine, Cedars-Sinai Medical Center, 8700 Beverly Blvd, Davis Room 7004, Los Angeles, CA 90048, USA

Email charles.cates@cshs.org

\begin{abstract}
Research using animals is a vital component to making life-saving discoveries in biology and health throughout the world. Research facilities face daily challenges in order to provide the utmost humane care and use of these precious animals. In the following paper, we examine five contemporary topics in regulatory and ethical management of laboratory animals: personhood of animals, chimpanzee use in research, contingency planning, freedom of information and open access laws, and social housing of research animals.
\end{abstract}

Keywords: chimpanzees, personhood of animals, social housing of research animals, contingency planning, FOIA

\section{Introduction}

The US has a rich and robust biomedical research enterprise. Considering both public and private investment, project funding exceeds US\$119 billion per year. ${ }^{1}$ Many of these projects involve research on animals and although the exact number is unknown, it is has been estimated that the number exceeds 25 million animals per year. ${ }^{2,3}$ This imposes a huge responsibility on researchers, institutions, caretakers, and veterinary staff to ensure proper care and responsible use of these valuable animals undergoing experimentation. In this quest, research institutions face a number of contemporary challenges which we will examine in the ensuing paragraphs. For the sake of organization, challenges have been delineated into two categories: ethical and regulatory. It is, however, recognized that the distinction is not sharp and in many instances regulatory and ethical concerns overlap. The reader may also recognize certain themes, such as improving humane care of research animals and the animal rights movement, that are pervasive among topics. The reader is encouraged to draw these connections and relate these insights to their own experience and situation as we examine five of the most important topics on in vivo animal research in the US today.

\section{Ethical issues}

The debate on the use of laboratory animals in the US continues to grow and evolve, particularly in recent years. In the mid-1960s, two important exposés on dog procurement for research appeared in two popular and widely distributed magazines. The story of Pepper the Dalmatian in Sports Illustrated and the revelation of atrocious conditions at a privately owned Maryland dog "farm" appearing in Life magazine spurred US government legislators into action resulting in passage of the 1966 Laboratory Animal Welfare Act (AWA). ${ }^{4-6}$ Around this time, the Animal Rights Movement began 
to take form and was strongly catalyzed by the publication of the book, Animal Liberation by Peter Singer in 1975. In the 1980s, the formation of People for the Ethical Treatment of Animals (PETA), the public revelation of multiple violations of the AWA involving monkeys in Silver Springs, MA, and the release of The Case for Animals Rights by Tom Regan further galvanized opponents of using animals in research. In the 1990s and 2000s, the animal rights movement spawned a number of activist groups such as the Animal Liberation Front which targeted researchers and research facilities with acts of violence and intimidation. Today, the Federal Bureau of Investigation (FBI) estimates there are some 250 animal rights groups in the US which raise $\$ 300$ million per year. ${ }^{7}$ Clearly, the debate of employing animals in research continues to rage in the US. In the following paper, we will take a look at two presently looming ethical issues regarding the use of laboratory animals in the US: personhood of animals and the use of chimpanzees in research.

\section{Personhood of animals} Introduction

Unquestionably, the animal rights movement in the US has grown over the last few decades. Once largely a philosophical movement, it has expanded to encompass components of legal strategy and judiciary action, to include filing lawsuits against research institutes and invoking requirements under the Freedom of Information Act and state public record laws. One tactic that has arisen is to attempt to abolish the status of animals as property. With this approach, proponents hope to gain "personhood" status for animals in order to afford them the same or similar rights as humans. In the following paragraphs, we will examine the philosophical underpinnings of the personhood argument, provide a recent history of actions to date, and examine strategies and expectations for the future.

\section{Philosophy and strategy}

The philosophical argument for granting legal personhood to animals primarily rests upon comparison of animals to "marginal cases" of humans. ${ }^{8}$ "Marginal cases" refers to humans that have a reduced capacity for autonomous behavior and decision making, namely the mentally handicapped, incapacitated persons, and children. As a society, we in the US have granted these individuals certain rights, despite them having a diminished capacity for autonomous living and decision making. At its core, the personhood movement seeks to gain rights for all entities capable of suffering, although as we will see shortly, it has initially focused on the most highly intelligent species such as nonhuman primates. Animal rights proponents have chosen to focus first on nonhuman primates for a number of reasons. First, nonhuman primates are highly intelligent and look closest in appearance to humans. In this way, it is a more natural extension of rights from humans to the group of animals most like humans. In addition, the research and economic impact of removing nonhuman primates from captivity may be less (or at least less readily recognized) than other species, particularly livestock and more commonly used research animals such as mice. ${ }^{9}$

\section{Recent history}

In the US, animal law has become a rapidly developing area in the legal field. Many developments illustrate the large upsurge in interest: an increase from 1-2 law schools offering animal law classes to greater than 90 since the 1990s, significant increase in journals focusing on animal law, and growth of the Animal Legal Defense Fund membership to over 100,000 members spread among chapters in 124 different law schools. ${ }^{9}$ The most recent example of the progression of the animal rights movement is the three legal personhood lawsuits filed in December 2013 by the Nonhuman Rights Project (NRP). ${ }^{10}$ The lawsuits were filed on behalf of four chimpanzees held in captivity in the state of New York, two privately held and two used in research settings. The lawsuits were enacted under the common law concept of the writ of habeas corpus, which allows a captured person to call upon legal assistance to challenge his or her captor's legal right to hold him or her. All three judges involved in the lawsuits quickly dismissed the applicability of the writ of habeas corpus ruling it applies only to human beings and the cases are currently in appeals processing. ${ }^{11}$ The strategy has been to gain a foothold in those states whose laws and previous rulings are most favorable to grant a writ of habeas corpus to an animal. Accordingly, the NRP continues to maintain a website which rates states on a 5-star scale based on the legal environment of the state toward consideration of giving animals rights. ${ }^{12}$

\section{Future}

For the future, the NRP intends to continue to file lawsuits in the most favorable states and encourage other attorneys to do so as well. For biomedical research, the ramifications of granting legal rights to animals are obvious: taken to the furthest extent, it would likely lead to abolishment of research on animals. The challenge then is to continue demonstrating the value of animal research and for institutions to maintain diligence in ensuring the highest ethical standards in research and welfare of laboratory animals under their care. 


\section{Chimpanzees in research}

\section{Introduction}

The US is one of the very few, if not the only, country in the world known to conduct invasive research on chimpanzees. Interestingly, although many countries have prohibited invasive chimpanzee research within their borders, they have not outlawed researchers from conducting chimpanzee research abroad. Since 2005, countries such as Italy, Denmark, Japan, South Korea, Canada, Australia, Belgium, France, and Spain have combined to commission 27 chimpanzee studies conducted in the US. It is estimated the National Institutes of Health (NIH) will spend approximately US $\$ 12$ million per year on caring for approximately 650 chimpanzees irrespective of whether they are on one of roughly 30 active research protocols, retired, or currently idle from research. ${ }^{13}$ Research is conducted at four main centers around the US with a fifth functioning as a long-term holding facility. The majority of federally funded studies target hepatitis viruses followed in turn by investigations into comparative genomics, neuroscience, HIV/AIDS, and behavior. Malaria, respiratory syncytial virus, and monoclonal antibody treatments compose a smaller number of studies as well. Although private sector data is limited, it is certain ongoing studies exist - particularly in the area of hepatitis $\mathrm{C}$, monoclonal antibody work and efficacy, and safety and pharmacokinetics of candidate therapeutics. ${ }^{14}$

\section{History}

The history of the use of chimpanzees in research finds its origins in the 1920s when Dr Robert Yerkes purchased two chimpanzees, Chim and Panzee, which he used for scientific studies in comparative psychology (Figure 1). Over the ensuing years, Yerkes established a research colony of chimpanzees known today as the Yerkes National Primate Research Center. ${ }^{15,16}$ In the 1950s, the US Air Force began purchasing chimpanzees to participate in the Space Program, ensuring spaceflight was safe for humans. After retirement of the space monkeys in the 1960s, the 1980s saw a renewed interest in chimpanzee research with the advent of the HIV epidemic and a search for the cure and prevention of AIDS. Most recently, biomedical research using chimpanzees has focused on comparative genomics, developing vaccines and therapeutics for hepatitis $\mathrm{C}$, and assessing monoclonal antibody treatments among others.

Throughout this time, interest in removing chimpanzees as subjects of invasive biomedical research gradually increased. The first real steps in the movement can be traced to the late 1960s and 1970s with the passage of the Animal Welfare Act of 1966, the Endangered Species Act of 1976, and the banning of the importation of chimpanzees to the US under the Convention on International Trade of Endangered Species in 1977. These legal actions were the first to legislate guidance and limitations on the use of chimpanzees in biomedical research. Since that time, we have seen the chimpanzee become listed as an endangered species, the prohibition against euthanizing chimpanzees no longer needed for experimental studies, the establishment of a retirement system for research chimpanzees, the cessation of federally funded breeding of chimpanzees, and the establishment a review board tasked to review chimpanzee biomedical research applications according to a set of strict guidelines. Furthermore, the NIH has committed to reducing the number of federally funded chimpanzees by $90 \%$, leaving a colony of 50 animals for use in research. ${ }^{17}$ The private sector has supported this movement as well. In January 2014, Merck and Company joined with 26 other biopharmaceutical companies in pledging to no longer financially support or conduct research on chimpanzees. ${ }^{18,19}$

\section{Issues}

With these developments, many challenges arise. Chimpanzees have contributed much to our knowledge of human physiology and disease, from ensuring safety of humans in spaceflight to protection of millions with the hepatitis B vaccine. Will important research such as this be limited or jeopardized? In addition, time and resources will be needed to explore and develop alternatives. The NIH has determined sufficient alternatives exist for the majority of current chimpanzee research, however, does note, "development of nonchimpanzee models requires continued support by the NIH" and "new, emerging, or reemerging disease ... may present challenges ... that defy non-chimpanzee models ... and may require the future use of the chimpanzee." ${ }^{\prime 4}$ Finally, the costs to transfer chimpanzees to retirement homes and to maintain large colonies of retired chimpanzees are not trivial. The original CHIMP Act allocated US\$30 million to establish and maintain chimpanzee retirement centers. ${ }^{20}$ This money was projected to run out in November 2013, so new legislation has been introduced (a second amendment to the CHIMP Act) to continue this funding. In addition, the NIH has been funding a US\$46 million (total funding through December 2013) contract to maintain a group of chimpanzees housed, but not undergoing experiments, at the Alamogordo Primate Facility in New Mexico. The NIH estimates current per diem rates for chimpanzees range from $\$ 42.70$ to $\$ 61.30 .{ }^{13}$ This could translate to approximately US\$10-12 million per year to maintain a colony of 644 retired chimpanzees. Given the 
1920s: Robert Yerkes of Harvard conducts first experiments in chimpanzees

1950s: Air Force imports chimpanzees for US space program

1966: Congress passes the Animal Welfare Act (AWA) governing use of research animals

1976: Endangered Species Act of 1973 (ESA) lists captive chimps as "threatened" species

1977: CITES bans import of chimpanzees

1985: AWA amended to include psychological well-being of nonhuman primates

1986: AIDS epidemic spurs NIH chimpanzee breeding program

1990: ESA updates wild-caught chimps as "endangered species"; captive are still "threatened"

1995: NIH established moratorium on federally-funded chimpanzee breeding

2000: CHIMP Act establishes US chimp sanctuaries and retirement program

2007: NCRR announces they will no longer fund chimp breeding effectively making the moratorium on breeding permanent

2010: (Mar) HSUS files petition to list captive chimps as "endangered" under the ESA (Oct) NIH announces move of 186 idle chimps back into research sparking public protest (Dec) NIH commissions Institute of Medicine (IOM) to assess necessity of chimp research

2011: IOM inquiry results spur NIH to drastically reduce federally-funded chimp research; a moratorium is put in effect for all new, renewed, or revised chimp research applications

2012: (Feb) NIH charges Council of Councils to give advice on implementation of IOM recommendations

(Oct) NIH announces plans to retire all (110) chimps at NIRC

(Dec) Nonhuman Rights Project submits writ of habeas corpus lawsuits, one of which involves two research chimps

2013: (Jan) NIH receives Council of Councils report

(Jun) NIH accepts majority of Council of Council recommendations: Chimpanzee

Research use Panel formed to recommend approval/disapproval of chimp studies; will retire nearly $90 \%$ of federally-owned chimps, with population of 50 in reserve

(Jun) Fish and Wildlife Service proposes rule to classify captive chimps as "endangered"; pending

(Oct) Amendment to CHIMP Act that will increase budget for retiring chimpanzees; passes Senate but pending House and Executive approval

2014: (Jan) Moratorium on chimp research lifted; NIH begins review of grant applications under new system

(Jan) Merck \& Co. and 24 other companies announce they will not use chimpanzees for biomedical research

Figure I Timeline of biomedical research in chimpanzees in the United States: 1920s to present.

Abbreviations: CITES, Convention on International Trade in Endangered Species of Wild Fauna and Flora; AIDS, acquired immune deficiency syndrome; NIH, National Institutes of Health; CHIMP, Chimpanzee Health Improvement, Maintenance, and Protection; NCRR, National Center for Research Resources; HSUS, the Humane Society of the United States; NIRC, New Iberia Research Center.

long lifespan (often exceeding 50 years) and complex nature of this species, developing, funding, and executing plans for the transfer and long-term care of chimpanzees will remain a challenge for the years ahead.

\section{Regulatory topics}

Due to a complex set of laws, policies, and guidelines, numerous regulatory issues confront those who conduct animal research in the US. In its most simplified form, two primary documents govern the humane care and use of laboratory animals in the US: the Animal Welfare Act (AWA) and its accompanying Regulations, and The Guide for the Care and Use of Laboratory Animals (the Guide). ${ }^{21-23}$ The AWA and Regulations serve as legal governance promulgating the US federal law first passed in 1966 to protect certain species and categories of animals. There are various exceptions; however, in general, the AWA covers warm-blooded animals used for research, teaching, and testing - and does not include mice and rats specifically 
bred for use in research. The AWA mandates establishment of an Institutional Care and Use Committee (IACUC) at each research facility. The committee serves as the administrative arm of the research program at the institution and is responsible for reviewing research protocols and ensuring compliance with regulatory guidelines. On the other hand, the Guide serves as regulatory guidance to fulfill requirements under Public Health Service (PHS) Policy for entities performing animal research funded via the PHS (the primary government funding arm for biomedical research in the US) and those wishing to be accredited by the Association for Assessment and Accreditation of Laboratory Animal Care, International (AAALACi). In contrast to the AWA, the PHS Policy covers all vertebrate animal species. AWA laws are enforced by the US Department of Agriculture (USDA) whereas PHS Policy is primarily enforced by the Office for Laboratory Animal Welfare (OLAW) - with or without USDA involvement depending on species involved. As one can see, a myriad of entities, laws, guidelines, and policies provide for a complex regulatory environment regarding the conduct of animal research in the US. The following is a discussion of three of the most pressing topics facing the administration of animal research programs in the US today: contingency planning, social housing of research animals, and records requests under the Freedom of Information Act and State Sunshine Laws.

\section{Contingency planning} Introduction

Although recently emerging as a hot topic for US research entities, contingency planning for research animals has been in the research community's collective conscience for many years. Even as early as 1965, the Guide for the Care and Use of Laboratory Animals called for 24-hour emergency care of animals, formulating standard operating procedures, and posting emergency contact information. ${ }^{24}$ Over the ensuing years, primarily due to a number of natural disasters enacting a major toll on several research operations, recommendations have become increasingly stronger and more specific. In December 2013, the emphasis culminated in the amendment of contingency planning language to the Animal Welfare Act Regulations. ${ }^{25}$ In the following paragraphs, we will look at a brief history of contingency planning, give an overview of the current requirements, and provide a discussion on the challenges that may be faced by research facilities.

\section{Background}

As previously noted, contingency planning for research animals is not a new concept. Facility accreditation guidelines appear in multiple, early versions of the Guide, and the AWA specifically lists criteria for responding to emergencies for marine mammals. Nevertheless, these early descriptions were minimal, receiving relatively little attention. It was not until 2005 when Hurricane Katrina emphatically spurred activity to overhaul contingency planning in the US that a true focus arose to formalize contingency planning for research institutes. Hurricane Katrina was the costliest natural disaster in US history amounting to US\$108 billion in property damages and the deaths of over 1,800 people. $^{26,27}$ Included in this devastation were research facilities. Katrina affected approximately 300 federally funded projects at New Orleans colleges and universities, cumulatively valued at more than $\$ 150$ million, including the LSU Health Sciences Center School of Medicine that reportedly lost approximately 8,000 laboratory animals. ${ }^{28}$ The impetus drove the USDA to action and by 2008 an initial proposal outlining an amendment to the AWA governing contingency planning for research facilities (among others, as we will see) was published in the US Federal Register. Several years later, in December 2013, the AWA was officially amended to promulgate contingency planning requirements for stewards of species covered under the AWA. ${ }^{25}$ The move was met with little fanfare outside of the communities directly affected until a Washington Post article highlighted the case of Marty the magician. ${ }^{29}$ Marty was a 27-year-old veteran magician who owned a rabbit which he used in magic shows for children. As a warm-blooded mammal being used for exhibit, the rabbit was covered under the AWA and consequently Marty was sent a notice by USDA inspectors to ensure he wrote a detailed contingency plan for the rabbit in the event of a disaster or emergency. Shortly after the online publication of the article, on July 31 2013, the USDA issued a stay on the new regulations in order to review requirements under the law, specifically as they apply to small operations such as Marty's. ${ }^{30}$ Subsequently, for now, US research facilities have a moratorium on the legal requirement to have formal, written contingency plans and regular, documented training for employees.

Due to the importance of preparing for emergencies and natural disasters, many research facilities have already begun to formulate, update, or formalize contingency plans and training for animals and animal caregivers. The presently stayed amendment to the AWA gives two main requirements: a formal, written contingency plan maintained at the facility and a formal training program for key employees on the contents of the contingency plan and how to respond to emergency or disaster. The planning document is not sent to or approved by the USDA. Rather, it is designed, scripted and 
maintained at the facility. Nevertheless, the document will be subject to inspection by the USDA and review of the document would become a component of the annual inspection process. The regulations call for a comprehensive, methodical analysis and detailed description of plans. At a minimum, five emergency situations must be addressed: electrical outage, HVAC failure, fires, animal escapes, and natural disasters (earthquake, hurricane, etc) most likely to occur in the region. Facilities must "outline specific tasks", give "detailed animal evacuation instructions", and have "provisions for providing backup sources of food and water as well as sanitation, ventilation, bedding, veterinary care, etc." ${ }^{25}$ In addition to the planning document, facilities must document training of employees on the general content of the planning document as well as specific roles and responsibilities therein. The contingency planning documents must be reviewed on an annual basis and both the planning document and training documentation "must be available to APHIS and any funding Federal agency representatives upon request." ${ }^{25}$ While it is certainly important to consider contingency operations to protect animals and research investment, proper adherence to the regulations will likely require significant and sustained investment of resources.

\section{Issues}

The first potential challenge is the increased manpower needed to create and maintain the plan and identify, train, and track personnel training. Responsibilities for creating and enacting a broad contingency plan may span many different departments and reach an advanced level of organizational complexity. Not only will animal care staff be involved, but investigator staff, IACUCs, environmental health and safety, police and fire departments, facilities maintenance (including electricians, plumbers, and HVAC personnel) as well. The plan will require regular review and update as new personnel arrive and others depart, and infrastructure is added, subtracted, or modified. Trainers will have to be identified and trained to instruct personnel on the requirements of the planning document. Administrative tasks will have to be assigned to track the training of key personnel who may be located throughout different departments and disparate locations at the institute. Ultimately, coordination of disaster preparedness activities and the approval of the contingency plan will require multiple levels of administrative review and a sizable investment of manpower to accomplish.

In addition to manpower, other resources may need to be allocated to meet the requirements of the regulations as written. As previously mentioned, the regulations call for provision of backup resources such as food, water, bedding, sanitation, and veterinary care - all of which take space, environmental monitoring, and documentation all their own. Additional supplies for sanitation and veterinary care will similarly require space allocation and, could prove to be costly to purchase and maintain, particularly considering expiration dates on disinfectants, drugs, and supplies. Based on the extent to which the regulations are interpreted, capital and space investments in adhering to the AWA amendment could be substantial.

Perhaps the greatest concern for institutions lies in the unknown: to what extent will these regulations be interpreted, what will be the expectations, and how will they be enforced? For example, the regulations require that a chain of command be identified by name or position title. Will there be any expectations of who these people must be or what qualifications they should have? What if an evacuation goes awry, will those in command be held directly responsible in some way? Another requirement is to provide backup provisions. Who will determine what adequate backup provisions are or how long they should last? Will research facilities ultimately be expected to invest in acquiring such provisions? Third, the regulations do not give separate consideration for typical emergencies (ie, fire, mechanical or electrical failure, animal escape) versus natural disasters such as hurricanes or earthquakes, and animal rights-related acts (vandalism, terrorist attacks). On one hand, local emergencies tend to be fairly straightforward, confined, and amenable to management according to prescripted standard operating procedures. Contrastingly, natural disasters are complex, uncontained and entire cities, states, and geographical regions struggle to properly prepare for such calamity. Finally, some question the effectiveness of USDA inspectors to adequately assess contingency plans. USDA inspectors of research facilities typically are veterinarians who have a background in clinical veterinary medicine. They have not been trained nor do they have experience in evaluating contingency plans. Research facilities will naturally question whether or not review of contingency plans can be fairly and knowledgeably executed by the current inspectors.

The USDA has provided some guidance on these issues. In the background information to the regulations, the USDA has emphasized compliance will be evaluated based only upon development of the planning document and timely training of involved employees. ${ }^{25}$ It continues by explaining no facilities will be required to make capital expenditures or structural improvements to comply with the regulation. The USDA has also peripherally addressed the issue of consequences if an institution's contingency plan fails. 
In a January 2013 Fact Sheet, the USDA suggests they understand plans may not always work, but the facility should incorporate lessons learned into future planning documents and ensure personnel are trained on these updates within 30 days. ${ }^{31}$ However, the answers seem to stop short of specifically addressing whether or not there will be consequences if a plan fails (or is not properly executed) and how the new regulations will be enforced. As for the capability of inspectors to determine if contingency plans are adequate, the USDA does not believe they will need to hire staff with specialized knowledge in emergency preparedness; rather, providing training to current inspectors should suffice.

Protecting animals and research investment in the event of emergency or natural disasters is of vital concern. Nevertheless, many questions remain about the future of formalized contingency planning to accomplish this measure. The indefinite stay imposed on the regulation is testament to the controversy and complexity of formulating such requirements. For the time being, research facilities are accomplishing preliminary steps in anticipation of official guidance and otherwise standing by to see what happens next.

\section{Freedom of Information Act/State Sunshine Laws Introduction and background}

In 1966, US President, Lyndon Johnson, signed the Freedom of Information Act (FOIA) into law. Originally intended as a first step toward ensuring US government transparency, the FOIA has since undergone a number of revisions. FOIA regulations were extended to the digital age with the enactment of the 1996 Electronic Freedom of Information Act under President Bill Clinton. Then in 2007, FOIA requests were elevated in prioritization by the Open Government Act signed by President George W Bush imposing consequences for agency noncompliance with a new FOIA 20-day response time. Most recently in 2009, Attorney General Eric Holder, under direction of President Barack Obama, issued new FOIA Guidelines ushering in a "New Era of Open Government" emphasizing transparency in government operations. ${ }^{32,33}$ Such has the reach of the FOIA regulation expanded, the acronym has evolved to include verb status (ie, "we've been FOIA'd") and the term broadly used to include reference to all information requests sent to non-federal facilities, despite the fact FOIA applies only to federal agencies. Today in the US, two sets of regulations, FOIA and state-specific open access laws (colloquially known as "sunshine laws") govern processing and replying to requests for information from research facilities by the public. FOIA as it strictly exists, applies only to federal agencies such as the National Institutes of Health
(NIH), US Department of Agriculture (USDA), Centers for Disease Control (CDC), and the Veteran's Administration (VA). FOIA requires institutions to respond to requests within 20 business days and provide as much information as possible save for nine exemptions designed to protect personal privacy as well as institutional proprietary information. A number of US federal agencies are responsible for oversight, funding, and conducting animal research, and therefore records pertaining to these activities may be requested under FOIA.

In keeping with the federal provisions, individual states have also passed laws which require state-supported entities such as colleges and universities to provide information requested by the public, the so-called open access or "sunshine" laws. Further complicating matters, sunshine laws are highly state-specific, may require variably increased or decreased transparency between states, and are typically more stringent than FOIA standards. Taken together, FOIA and open-access laws provide recourse for those citizens who wish to review documents pertaining to the care and use of laboratory animals in public institutions across the US while at the same time attempting to preserve personal privacy and intellectual property of the institution.

\section{Issues}

Two primary issues arise in regard to the FOIA and sunshine laws. First, the manpower and resources needed to complete a request can be quite substantial. Second, the information gathered from these requests has at times been used for nefarious activities directed against animal researchers. We will take a separate look at each of these concerns in the following paragraphs.

FOIA and open-access laws are detailed and complex. Interpretation of what can, should, or must be released can be difficult and controversial. The routing of a request and response itself can be equally daunting as it may need to traverse multiple offices and undergo numerous revisions. Initially, requests may arise through various avenues but are usually then funneled to a central point of contact (such as a legal office, public relations, and/or records management division) for review and dissemination. Generally, three main entities will assist the records processing points of contact to access and prepare documents for release: the Institutional Animal Care and Use Committee, laboratories involved with the animal research activities requested, and the attending veterinarian plus associated personnel responsible for veterinary care of the animals. These groups will work together to identify, collect, review, and redact the requested information in preparation to submit to the requestor. Often, 
requests are broadly worded and involve reviewing hundreds of pages and multiple sets of documents spanning multiple years. Although facilities may charge minimal administrative fees to recoup the cost of making copies, man-hours incurred during the process are nonchargeable. For example, the National Institutes of Health (the primary US government funding arm for biomedical research) recently reported FOIA requests processing and litigation-related costs exceeded US\$3.3 million as compared to less than US\$22,000 collected in fees. ${ }^{34}$ In general, from the facility standpoint, a FOIA request is a nonreimbursable, labor-intensive process which diverts substantial resources from normal duties. Striving for the right balance of providing transparency, protecting personal privacy and institutional interests, and allocating resources while not compromising operations is a major challenge animal research facilities face in responding to open-access information requests in the US today.

Even more concerning, however, is the fact that information garnered from FOIA and open access laws has been used by animal rights extremists to perpetrate terrorist acts against scientists involved in animal research. Between 1995 and 2010, there were a total of 108 arsons and bombings committed by animal rights extremists. ${ }^{7}$ Activists targeted many different sites including campus facilities and private homes of researchers. In addition, at least one state court has recognized a link between the release of open-access records and an increase in violent crime against specific researchers immediately following the release. In a recent ruling upheld by the state of California appellate courts, a judge sided with the University of California, Los Angeles in a suit brought forth by animal right activists insisting certain research records be made available under open-access laws. The judge ruled there is a "causal nexus between disclosure of animal research records and subsequent attacks on the researchers identified in such records after they are disseminated to the public." ${ }^{32}$ Due to these realities, awareness and resources employed to protect researchers and research facilities are at an all-time high and will likely only continue to increase.

Over the ensuing years, it is clear research institutions will continue to face substantial challenges in responding openly and accurately to information requests while sustaining viable operations and protecting the privacy of researchers and animal caregivers.

\section{Social housing of research animals Introduction}

Social housing of conspecific animals (the concept that species which cohabitate in nature experience improved welfare if housed in pairs or groups in the laboratory setting) has become an area of intense focus in the US animal research community over the past few years. During recent times, the mindset has shifted from the default position to singly house animals (with case-by-case consideration for group housing) to establishment of pair or group housing as the standard of care. The transformation has been driven by regulatory direction and other guidance, most prominently the Animal Welfare Act and Regulations, the Guide, and AAALACi position statements. We will now briefly look at the history which has led us up to this point.

\section{History}

The roots of the movement toward social housing of animals might well be traced to the early 1980s when Alex Pacheco from the animal rights group, People for the Ethical Treatment of Animals (PETA), went undercover in a laboratory in Silver Springs, Maryland. The fervor and controversy wrought by his allegations of animal abuse of 17 rhesus monkeys, arguably was the major impetus behind passing the 1985 amendment to the AWA. ${ }^{35,36}$ The amendment, dubbed the "Improved Standards for Laboratory Animals Act", called for research facilities to establish programs to ensure, among other things, the psychological well-being of nonhuman primates. ${ }^{37}$ The USDA subsequently interpreted the new law to include social interaction as an integral component of psychological well-being and that institutions must address such social grouping in the context of an overall approach to the care of nonhuman primates. ${ }^{22}$ The statute was the first legal requirement to consider social housing of any species.

Although such entities as the NIH immediately took initial steps to comply with the new law, the implementation of social housing for NHPs was slow to unfold. This was in part due to the concurrently released 1985 Guide's reluctance to provide succinct guidance on social housing of animals, essentially avoiding the topic by reporting that little objective evidence existed to establish recommendations. At around the same time, a study was conducted to evaluate social housing of aged rhesus macaques. ${ }^{38}$ The results were not promising: 10 of 13 animals were reported to have been seriously wounded due to fighting and one animal even died due to injuries sustained. ${ }^{39}$ Despite the dubious early outcomes, the scientific and veterinary community gradually began to acknowledge the benefits of group housing and developed strategies to improve success. ${ }^{40}$

These developments culminated in a major update to social housing in the 1996 Guide - a complete revision which captured the evolving mindset. No longer was the perception 
of limited scientific and practical data for why and how to socially house research animals. Instead, an entire section was now dedicated to "Behavioral Management" proclaiming that group housing was "desirable" and instructed that "social animals should be housed in physical contact with conspecifics." ${ }^{41}$ Fifteen years later, the 2011 Guide solidified this position and for the first time introduced the concept of pair and group housing as the default accommodation..$^{23}$ The guidance provides for the fact that circumstances may dictate singly housing animals, however, this should be the exception to the rule and thoroughly documented in animal records. It is expected the attending veterinarian of the research facility manages, reviews, and documents exceptions due to animal welfare (such as fighting, quarantine, health monitoring) whereas IACUCs are to handle exclusions for scientific reasons (data consistency, behavior influences, etc). These entities in conjunction with animal caregivers, scientists, facility managers, and executive leadership are expected to provide opportunities for conspecifics to interact and abide together. AAALACi quickly fell in line and issued a position statement reiterating this view, establishing a deadline of three years to comply with the new standard. ${ }^{42}$ So with the publishing of the Guide in 2011 and subsequent AAALACi-issued deadline, there has been a flurry of activity as research facilities across the US update their programs to be fully compliant by September 2014. These mandates of course are not without their challenges. In the following paragraphs we will take a look at four challenges research facilities face in implementing a robust program for social housing of research animals.

\section{Fighting}

First, animal caregivers must successfully balance the social benefits of species cohabitation with the negative stressors of aggression, fighting, and discord. It is not uncommon that cohoused animals fight and inflict severe injury even to the point of death or forced euthanasia. Most often, situations are species, sex, and even age-dependent. Chief among these are incidents of genitalia mutilation by male rabbits, hierarchy establishment amongst pigs (particularly boars), puncture wounds and crush injuries from macaque bites, and male mouse infighting. Various mitigation measures have been explored and implemented; however, significant challenges remain to ensure social housing is a positive experience and not a source of injury or distress to the animal.

\section{Health and disease}

Second, prevention of communicable disease as well as maintaining and tracking the health of individual animals is much more difficult in a group setting. Blood-borne and other infectious disease spread by intimate contact is much more likely to spread in a social-housing arrangement. Likewise, assessing and tracking illness is greatly complicated. In a group setting, assessing such clinical parameters as individual food and water intake, stool and urine production, and character are often impractical to the point of impossibility. Bandaging, catheters, or other external fixtures may be subject to manipulation or removal by cage mates. Dominant animals monopolizing food may become a concern as well. Clearly, social housing of animals presents increased difficulties in health monitoring and prevention of disease spread.

\section{Research data}

Third, researchers must be aware of and account for how group housing may impact their studies and affect comparison to historical data. The most obvious drawback for researchers may be delayed studies, altered data, or lost animals due to treatment for injury or mortality. Potentially more subtle influences are elevated or decreased stress responses, activity level, and alternative behaviors affecting data acquisition and experimental consistency. A real challenge arises when a group-housed animal must be singly housed due to injury or illness and is therefore exposed to an entirely unique living condition as compared to other animals on the study. Facilities then are challenged to balance the benefits of providing the social housing experience while ensuring the 3 Rs principles of refinement of procedures and reduction of animal numbers are not compromised by having to delay or repeat experiments.

\section{Capital and manpower cost}

Finally, costs of implementing such programs may be high, both in terms of capital expenditures and increased manpower. The laboratory setting is an artificial environment and as such is often much different than the natural environment of social animals. Of particular concern is the limitation of space. In nature, animals tend to have much more space in which to interact with conspecifics. This allows for animals to maintain space between others if necessary and escape and avoid aggression. Similarly, there is a general lack of hiding spaces for animals housed together in the laboratory as compared to in nature. Cages and pens are generally bare and areas for retreat sparse - there is often no place to run and no place to hide. In social housing, facilities may attempt to rectify this by creating or purchasing larger housing spaces and adding forms of enrichment which mimic natural hiding places. However, these modifications may be quite costly 
for the facility. In addition to material expenditure, socially housing animals can become a decidedly labor-intensive process. Planning and executing pairings or groupings, maintaining larger and more complex living quarters, cleaning and maintaining enrichment devices, education and training of staff, surgery and treatments for fight wounds, and processing increased documentation contribute to elevated manpower costs. Advanced measures to reduce aggression and prevent pregnancy such as castration and vasectomy of some species may add significant additional cost to the endeavor. While capital and manpower expense are not to be used as primary justification to eschew social housing, it cannot be avoided as a critical consideration in implementing an effective yet practical social housing program.

Nevertheless, despite these drawbacks and concerns, experience and science have shown in the right circumstances, social housing of animals is highly beneficial. Social housing can buffer stressful situations, reduce stereotypies, increase exercise, and expand species-specific behavior and cognition. ${ }^{43,44}$ As we look to the future, research facilities will need to become increasingly attentive and creative in fashioning an appropriate and safe social environment for their animals.

\section{Conclusion}

The biomedical research environment in the US is undoubtedly vast and complex. The preceding examination of contemporary topics on animals used in biomedical research gives only a glimpse of the many challenges faced by research institutions on a daily basis. Despite an intricate and everchanging landscape, one thing remains certain: each unique research facility must strive to be nimble, dedicated, and diligent to adapt to constantly evolving regulatory standards and continue to provide a safe, healthy, and humane environment for all animals under their care.

\section{Disclosure}

The authors report no conflicts of interest in this work.

\section{References}

1. Chakma J, Sun GH, Steinberg JD, Sammut SM, Jagsi R. Asia's ascent-global trends in biomedical R\&D expenditures. $N$ Engl J Med. 2014;370(1):3-6.

2. Annual Report: Animal Usage by Fiscal Year 2009 and 2010. Animal and Plant Health Inspection Service, United States Department of Agriculture; 2011.

3. The Hastings Center. Fact Sheet: Animals Used in Research in the United States; 2014. Available from: http://animalresearch.thehastingscenter.org/ facts-sheets/animals-used-in-research-in-the-united-states/\#refmark-***. Accessed November 12, 2014.

4. Phinizy C. The lost pets that stray to labs. Sports Illustrated. 1965.

5. Silva M. Concentration camps for dogs. Life. 1966.
6. National Research Council. Scientific and Humane Issues in the use of Random Source Dogs and Cats in Research. Washington, DC: National Academies Press; 2009. Available from: http://www.ncbi.nlm.nih. gov/entrez/query.fcgi? $\mathrm{cmd}=$ Retrieve $\& \mathrm{db}=$ PubMed $\&$ dopt=Citation $\& 1$ ist_uids=20662127. Accessed July 28, 2010.

7. An Overview of Bombing and Arson Attacks by Environmental and Animal Rights Extremists in the United States, 1995-2010. National Consortium for the Study of Terrorism and Responses to Terrorism (START); Available from: http://www.start.umd.edu/publication/ overview-bombing-and-arson-attacks-environmental-and-animalrights-extremists-united. Accessed November 12, 2014.

8. Cupp RL. Children, Chimps, and Rights: Arguments from "Marginal" Cases. Selected Works [of Richard Cupps]. Available from: http://works. bepress.com/richard_cupp/1. Accessed November 12, 2014.

9. Cupp RL. A dubious grail: Seeking Tort law expansion and limited personhood as a stepping stones toward abolishing animals' property status. SMU Law Review. 2007;60:3-54.

10. VaughanB,WiessnerD. NewYork lawsuitseeks 'legalpersonhood' for chimpanzees. Available from: http://www.reuters.com/article/2013/12/02/ us-usa-chimpanzees-lawsuit-idUSBRE9B10UE20131202. Accessed November 12, 2014.

11. Conlon K. Chimpanzee personhood effort fails first legal tests in New York. Available from: http://www.cnn.com/2013/12/09/us/newyork-chimps-personhood/. Accessed November 12, 2014.

12. Nonhuman Rights Project. State-by-State [legal analysis]. Available from: http://states.nonhumanrights.org/category/about/. Accessed July 22, 2014.

13. Preliminary Costs for Maintaining Humane Care and Welfare of Chimpanzees. National Institutes of Health (US). Available from: http:// dpcpsi.nih.gov/orip/cm/chimpanzee_maintenance. Accessed November 12, 2014.

14. Altevogt B, Pankevich D, Shelton-Davenport M, Kahn J; Institute of Medicine and National Research Council Committee on the Use of Chimpanzees in Biomedical and Behavioral Research. Chimpanzees in Biomedical and Behavioral Research: Assessing the Necessity. The National Academies Collection: Reports funded by National Institutes of Health, Washington, DC; 2011.

15. Yerkes RM. Almost Human. New York, NY: Century; 1925.

16. Yerkes National Primate Research Center. History [The origins of the Yerkes National Primate Research Center]. Available from: http://www. yerkes.emory.edu/about/history.html. Accessed November 12, 2014.

17. Announcement of Agency Decision: Recommendations on the Use of Chimpanzees in NIH-Supported Research, (NOT-OD-13-078). Planning, and Strategic Initiatives, Division of Program Coordination, National Institutes of Health; 2013.

18. Animal Research. Merck and Company. Available from: (http:// www.merckresponsibility.com/focus-areas/access-to-health/ research-development/animal-research/. Accessed November 12, 2014.

19. Companies with Invasive Chimpanzee Research Policies. Humane Society of the United States;. Available from: http://www.humanesociety. org/issues/chimpanzee_research/tips/companies_chimpanzee_ policies.html?credit=web_id497655620\#.UuqEYaMo69I). Accessed November 12, 2014.

20. United States Public Law 106-551: Chimpanzee Health Improvement, Maintenance and Protection Act. 2000.

21. Animal Welfare Act and Amendments. US Code, Title 7: Chapter $54-$ Transportation, Sale, and Handling of Certain Animals. 1966.

22. United States Animal Welfare Act Regulations. Title 9 - Animals and Animal Products, Volume 1, Subchapter A - Animal Welfare. 2009.

23. Guide for the Care and Use of Laboratory Animals. 8th ed. Washington, DC: The National Academies Press; 2011.

24. Committee on the Guide for Laboratory Animal Facilities Care, Institute of Laboratory Animal Resources. Guide for Laboratory Animal Facilities and Care. Animal Facilities Standards Committee, Animal Care Panel, Animal Resources Branch, National Institutes of Health; 1965. Available from: http://catalog.hathitrust.org/api/volumes/ oclc/8279569.html. Accessed November 12, 2014. 
25. Animal and Plant Health Inspection Service. 9 CFR Parts 2 and 3 Final Rule: Handling of Animals; Contigency Plans. Federal Register, United State Department of Agriculture; 2012.

26. Knabb R, Rhome J, Brown D; National Hurricane Center. Hurricane Katrina: August 23-30, 2005 (Tropical Cyclone Report). United States National Oceanic and Atmospheric Administration's National Weather Service; 2005.

27. Blake ES, Landsea CW, Gibney EJ; National Hurricane Center. The Deadliest, Costliest, and Most Intense United States Tropical Cyclones from 1851 to 2010 (And Other Frequently Requested Hurricane Facts) (NOAA Technical Memorandum NWS NHC-6). United States National Oceanic and Atmospheric Administration's National Weather Service. Available from: http://www.nhc.noaa.gov/pdf/nws-nhc-6.pdf. Accessed November 12, 2014.

28. Barclay L. Research lost in Katrina flood: a newsmaker interview with Paul K. Whelton, MD, PhD. Available from http://www.medscape.com/ viewarticle/513289\#1. Accessed November 12, 2014.

29. Fahrenthold DA. Watch him pull a USDA-mandated rabbit disaster plan out of his hat. The Washington Post. July 16, 2013.

30. Animal and Plant Health Inspection Service. Handling of Animals: Contingency Plans; Stay of Regulations, 9 CFR Part 2, (Document Number: 2013-18524). Federal Register, United States Department of Agriculture. Available from http://www.regulations.gov/\#! documentD etail;D=APHIS-2006-0159-0214. Accessed November 12, 2014.

31. Animal and Plant Health Inspection Service. Fact Sheet: Questions and Answers-Final Rule on Contingency Plans for Regulated Entities. United States Department of Agriculture; 2013. Available from: http:// www.aphis.usda.gov/animal_welfare/content/printable_version/ contingency_rule_faq.pdf. Accessed November 12, 2014.

32. Institute of Medicine, National Research Council (US). International Animal Research Regulations: Impact on Neuroscience Research: Workshop Summary. Washington, DC: National Academies Press; 2012. Available from: http://www.ncbi.nlm.nih.gov/books/NBK100123/. Accessed November 12, 2014.

33. Office of Information Policy, FOIA Post. President Obama's FOIA Memorandum and Attorney General Holder's FOIA Guidelines: Creating a "New Era of Open Government". United States Department of Justice. Available from: http://www.justice.gov/oip/ foiapost/2009foiapost8.htm. Accessed November 12, 2014.
34. Cornell SR; Freedom of Information Officer, National Institutes of Health. Freedom of Information Report - Fiscal Year 2013. National Institutes of Health. Available from: http://www.nih.gov/icd/od/ foia/annualreports/annualreport_2013.pdf. Accessed November 12, 2014.

35. Benjamin A, Jean L. Legislative History of the Animal Welfare Act: Introduction. Animal Welfare Information Center, National Agriculture Library, United State Department of Agriculture. Available from: http:// awic.nal.usda.gov/legislative-history-animal-welfare-act/intro. Accessed November 12, 2014.

36. Carlson P. The strange case of the silver spring monkeys. The Washington Post. February 24, 1991.

37. United States Public Law 99-198, Food Security Act of 1985, Subtitle FAnimal Welfare: "The Improved Standards for Laboratory Animals Act".

38. Bayne K. A historical perspective on social housing. Enrichment Record. 2014;18:8-11.

39. Line S, Morgan K, Roberts J, Markowitz H. Preliminary comments on resocialization of aged rhesus macaques. Lab Prim News. 1990;29(1): $8-12$.

40. Reinhardt V, Liss C, Stevens C. Social housing of previously singlecaged macaques: what are the options and the risks?. Animal Welfare. 1995;4:307-328

41. Guide for the Care and Use of Laboratory Animals. 7th ed. Washington, DC: The National Academies Press; 1996.

42. Association for the Assessment and Accreditation of Laboratory Animal Care. Position Statement on Social Housing; 2011. Available from: http://www.aaalac.org/accreditation/positionstatements. cfm\#social. Accessed November 12, 2104.

43. Lutz CK, Novak MA. Environmental enrichment for nonhuman primates: theory and application. ILAR J. 2005;46(2):178-191.

44. Bayne KA. Environmental enrichment of nonhuman primates, dogs and rabbits used in toxicology studies. Toxicol Pathol. 2003;31(Suppl) $132-137$.
Open Access Animal Physiology

\section{Publish your work in this journal}

Open Access Animal Physiology is an international, peer-reviewed, open access journal publishing original research, reports, reviews and commentaries on all areas of animal physiology. The manuscript management system is completely online and includes a very

\section{Dovepress}

quick and fair peer-review system. Visit http://www.dovepress.com/ testimonials.php to read real quotes from published authors. 